\title{
ANÁLISE DOS RESULTADOS DA ATIVIDADE LEITEIRA: CUSTO HISTÓRICO VERSUS VALOR JUSTO DOS ATIVOS BIOLÓGICOS
}

\author{
Silvana Dalmutt Kruger ${ }^{1}$ \\ Catiane Ortolan ${ }^{2}$ \\ Elisandra Henn Diel ${ }^{3}$ \\ Fábio José Diel ${ }^{4}$ \\ Sady Mazzioni ${ }^{5}$
}

\begin{abstract}
RESUMO
O estudo tem por objetivo evidenciar a mensuração contábil da atividade leiteira comparando os critérios de avaliação pelo custo histórico e valor justo. A pesquisa foi realizada por meio de um estudo de caso em uma propriedade rural do oeste de Santa Catarina, com análise de dados de cunho qualitativo. Por meio da elaboração e utilização do Balanço Patrimonial e da Demonstração do Resultado do Exercício pode-se observar o resultado econômico da atividade leiteira, sendo a receita de $R \$$ 1,05 por litro vendido, o custo de $R \$ 0,39$ e o lucro por litro de $R \$ 0,66$ no período observado. Verificou-se que o patrimônio total no Balanço Patrimonial é aproximadamente $14 \%$ maior quando utilizada a mensuração pelo valor justo em comparação com a mensuração com valores do custo histórico. Os resultados, de modo geral, evidenciam a importância da utilização da contabilidade no processo de análise dos custos das atividades desenvolvidas no meio rural, bem como, da importância da utilização do Pronunciamento Contábil CPC 29 como critério de avaliação e mensuração dos ativos biológicos, visando evidenciar adequadamente o patrimônio das entidades rurais.
\end{abstract}

Palavras-chave: ativos biológicos, contabilidade rural, CPC 29, custo histórico, valor justo.

\footnotetext{
${ }^{1}$ Graduada em Ciências Contábeis (Unochapecó), Mestra em Contabilidade (UFSC), Doutoranda em Contabilidade (UFSC), professora do Curso de Ciências Contábeis (Unochapecó). Email:

silvanak@unochapecó.edu.br

${ }_{2}^{2}$ Graduada em Ciências Contábeis (Unochapecó). Email: catty_id@unochapecó.edu.br

${ }^{3}$ Graduada em Ciências Contábeis (Unochapecó), Mestre em Ciências Contábeis (FURB). Professora do Curso de Ciências Contábeis (UCEFF). Email: elihenn@unochapecó.edu.br

${ }^{4}$ Graduado em Ciências Contábeis (Unochapecó), Mestre em Ciências Contábeis (FURB), professor do Curso de Ciências Contábeis (Unochapecó). Email: f_diel@unochapecó.edu.br

${ }^{5}$ Graduado em Ciências Contábeis (UNOESC), Mestre em Ciências Contábeis e Doutorando em Administração e Ciências Contábeis (FURB), professor do curso de Ciências Contábeis (Unochapecó). Bolsista do FUMDES. Email: sady@unochapecó.edu.br
} 


\title{
ANALYSIS OF RESULTS OF DAIRY ACTIVITY: HISTORY VERSUS COST FAIR VALUE OF BIOLOGICAL ASSETS
}

\begin{abstract}
The study aims to highlight the accounting measurement of dairy farming comparing the assessment criteria at historical cost and fair value. The survey was conducted through a case study on a rural property west of Santa Catarina, with data analysis a qualitative approach. From the study it can be seen the production costs of dairy farming, comprising the supply, maintenance and manpower squad and the depreciation of the asset items. Through the development and use of the Balance Sheet and Statement of Income can observe the economic results of dairy farming, with an income of $R \$ 1,05$ per liter sold, the cost of $R \$ 0,39$ and profit per liter of $R \$$ 0,66 in the observed period. The results generally show the importance of using accounting on the cost analysis activities in rural areas process and the importance of using accounting pronouncement CPC 29 as a criterion for evaluation and measurement of biological assets, in order to adequately highlight the heritage of rural entities.
\end{abstract}

Keywords: biological assets, CPC 29, fair value, historical costs, rural accounting, .

\section{INTRODUÇÃO}

A contabilidade visa fornecer informações úteis aos seus usuários, para auxiliar no processo de tomada de decisões que conduzam às entidades a resultados satisfatórios, no intuito de garantir sua continuidade. Segundo ludícibus (2010), a Contabilidade tem como objetivo básico fornecer informações para a tomada de decisões e se preocupa com a mensuração dos itens patrimoniais e com a situação econômico-financeira das entidades.

No entanto, as formas de avaliação do patrimônio de uma empresa são variadas, por este motivo muito se tem discutido sobre as medidas para mensurar e avaliar o valor de determinados ativos, como é o caso dos ativos biológicos.

O Pronunciamento Contábil CPC 29 (2009) emitido pelo Comitê de Pronunciamentos Contábeis, exige que as empresas exploradoras de ativos biológicos (definidos como animais e plantas vivos) mensurem tais ativos a valor justo. A normativa define valor justo como o valor pelo qual um ativo pode ser negociado, ou um passivo liquidado, entre partes interessadas que se disponham a realizar tal transação.

Assim sendo, a base de mensuração dos ativos biológicos passou do custo histórico para o valor justo. Tal condição traz peculiaridades acerca da avaliação dos ativos biológicos, considerando-se que o processo de maturação e determinadas fases de crescimento ou desenvolvimento possuem especificidades, e nem sempre possuem mercado ativo para identificação do seu valor justo.

Paulo et al. (2011) evidenciam que uma das mudanças resultantes do CPC 29 é a obrigatoriedade de se reconhecer a cada exercício social os impactos nos resultados decorrentes das variações no valor justo. Ainda, mencionam que se antes o mercado de ativos biológicos já sofria com a volatilidade dos preços devido às peculiaridades desses produtos, tal volatilidade não era imediatamente repassada aos demonstrativos financeiros. Porém, com a adoção do CPC 29, as empresas são 
obrigadas a reconhecer variações nos valores de seus ativos biológicos e registrar os resultados, independente da realização de receitas.

De acordo com Marion (2012), caso uma empresa julgue que não há mercado confiável para fazer a mensuração por meio do valor justo, a ela é facultado continuar avaliando seus estoques a custo de formação ou custo histórico.

A contabilidade rural oferece recursos para mensurar os resultados das atividades desenvolvidas no meio rural. No entanto, ainda carece aos gestores rurais um conhecimento mais adequado dos artefatos que a contabilidade dispõe, a fim de incorporar os benefícios que pode proporcionar ao processo decisório. Dentro deste contexto o estudo pretende responder a seguinte problemática: Quais as principais diferenças na mensuração contábil verificada entre os critérios de avaliação pelo custo histórico e valor justo dos ativos biológicos relacionados à atividade leiteira? $\mathrm{O}$ objetivo é evidenciar a mensuração contábil da atividade leiteira comparando os critérios de avaliação pelo custo histórico e valor justo.

O estudo de Kruger et al. (2014), evidencia a falta de controles e da utilização da contabilidade na análise e acompanhamento das atividades desenvolvidas no meio rural. Neste sentido, justifica-se a relevância do estudo no intuito de orientar os gestores da atividade leiteira na análise das informações contábeis, bem como, a partir dos resultados evidenciar as diferenças entre a avaliação dos ativos biológicos pelo custo histórico e valor justo. Considera-se ainda, as alterações nos padrões nacionais de contabilidade, mais especificamente nos padrões que regem os procedimentos sobre os ativos biológicos (inclusive gado leiteiro), os quais motivaram esta pesquisa, tendo em vista que tais alterações são resultantes de um processo de adequação aos pronunciamentos emitidos pelo Internacional Accounting Standards Board - IASB, fruto da convergência das normas contábeis brasileiras às novas normas internacionais, a qual orienta a normativa CPC 29.

\section{CONTABILIDADE RURAL}

A contabilidade é a ciência de controle e planejamento patrimonial, estudada de forma geral ou específica, adaptando-se as necessidades de cada setor, aplicada as pessoas físicas ou jurídicas. De acordo com Crepaldi (2012), um dos principais sistemas de controle e informação das empresas rurais é a contabilidade rural, sendo que a partir da mesma é possível verificar a situação patrimonial, sob os mais diversos enfoques, como a análise de estrutura, evolução, solvência, retorno dos investimentos, garantia de capital próprio e de terceiros, entre outras.

Conforme Marion (2012), a contabilidade rural possui a finalidade de estudar e controlar o patrimônio, para gerar e fornecer informações necessárias para tomar decisões e contribuir nas tendências futuras. No entanto, para analisar os resultados, é necessário elaborar controles, identificar as condições de mercado e dos recursos naturais, que garantirá ao empresário rural os elementos básicos para o desenvolvimento de sua atividade econômica.

Conforme Crepaldi (2012) torna-se importante a geração de informações acerca dos resultados das atividades desenvolvidas no meio rural, no entanto, a contabilidade rural no Brasil ainda é pouco utilizada, tanto por parte dos profissionais contábeis, quanto pelos produtores rurais, devido à falta de conhecimento dos gestores rurais e pela ausência de profissionais contábeis com especialização neste ramo de atuação. Muitos destes gestores rurais tendem a desenvolver técnicas de controle baseadas em experiências passadas, desconsiderando informações eficazes e coerentes. A falta da documentação e de relatórios que comprovem os 
fatos (compra, venda, produção, etc.) são elementos que dificultam o uso da contabilidade no meio rural.

Toda entidade quando utiliza instrumentos de controle e análise de resultados, pode apresentar melhores resultados, porém, existem vários fatores para que a contabilidade não seja utilizada de forma adequada nas entidades rurais, dentre eles está à insuficiência de profissionais na divulgação de tecnologias administrativas e a falta de conhecimento sobre a contabilidade gerencial no meio rural. De acordo com Crepaldi (2012), há a necessidade de atualização no gerenciamento das empresas rurais, por meio de novas tecnologias que permitam aos produtores rurais obter rendimentos adicionais, acompanhar os resultados e atuar na minimização dos custos de produção.

Santos, Marion e Segatti (2002) destacam que quanto maior for o conhecimento do administrador a respeito da estrutura e do funcionamento da produção, maiores serão as chances de melhoria dos resultados econômicos. No entanto, para tal análise é preciso o acompanhamento dos processos e o registro com base em documentos hábeis.

Os gestores rurais que souberem usufruir adequadamente das informações contábeis terão em mãos instrumentos que permitem tomar decisões estratégicas e ter maiores probabilidades de acertos relacionados à lucratividade das atividades desenvolvidas. A contabilidade fornece artefatos que contribuem na avaliação do desempenho econômico das atividades rurais e a perenidade das atividades rurais.

Simonetti et al. (2013) indicam a importância da agricultura familiar e das pequenas propriedades rurais, tanto na diversificação das atividades econômicas, como na promoção do desenvolvimento regional, especialmente dos pequenos e médios municípios.

Santos, Marion e Segatti (2002) descrevem que a atividade agropecuária requer um sistema de informações próprio, o que deve considerar suas peculiaridades. Oliveira (2010) argumenta que se o produtor rural utilizar as informações fornecidas pela contabilidade terá condições de controlar os custos e avaliar os resultados por atividades desenvolvidas, mas principalmente, estabelecer planos e traçar estratégias que levem a propriedade rural rumo à eficiência da produção, mediante a observação das especificidades de cada tipo de cultura, do mercado e da tecnologia mais adequada para as atividades desenvolvidas.

Portanto, é por meio das informações geradas pela contabilidade que os produtores rurais podem obter informações para controlar seus custos e os resultados das atividades, podendo traçar novas estratégias para futuras melhorias e corrigir os pontos falhos dos processos produtivos (KRUGER, et al., 2014).

Para Silva (2009, p. 30), "a empresa rural é uma unidade de produção que possui elevado nível de capital de exploração e alto grau de comercialização, tendo como objetivo técnico a sobrevivência, o crescimento e a busca do lucro". Conforme Crepaldi (2012) a empresa rural é um setor de produção em que são exercidas atividades que dizem respeito às culturas agrícolas, a pecuária ou as culturas florestais, com a finalidade de obtenção de renda. Segundo Marion (2012, p. 02), "empresas rurais são aquelas que exploram a capacidade produtiva do solo por meio do cultivo da terra, da criação de animais, e da transformação de determinados produtos agrícolas".

O planejamento é a parte essencial da gestão das empresas, por isso podese considerar três fatores de produção imprescindíveis para uma empresa rural. De acordo com Crepaldi (2012): a terra, o capital e o trabalho. Na terra é onde se aplicam os recursos e se trabalha para obter produção. O capital é o conjunto de bens aplicados sobre a terra com a intenção de aumentar a produtividade. $O$ trabalho é conjunto de atividades desempenhadas pelo homem, como administrar, 
cuidar dos animais, entre outras atividades necessárias para o desenvolvimento da atividade.

Segala e Silva (2007) destacam que a contabilidade é uma ferramenta gerencial fundamental, permitindo o planejamento, controle e a tomada de decisão, auxiliando na evolução do setor, principalmente nas atribuições de administração financeira, controle de custos, diversificação e comparação de resultados. Santos, Mairon e Segatti (2002) afirmam que para ter sucesso, o empresário rural necessita das premissas básicas da administração, que são: planejar, organizar, dirigir e controlar, mas também precisa das informações em tempo hábil para o processo decisório.

Considerando as inúmeras inovações tecnológicas e a busca constante do mercado por qualidade e preço, exige-se dos gestores rurais a implantação de novas estratégias e técnicas produtivas para viabilizar melhorias do processo produtivo, na busca por menores custos e maior qualidade.

Para Crepaldi (2012), no meio rural, considerando as múltiplas atividades desenvolvidas e o volume financeiro das operações, constitui-se na realidade em empresa, apesar de nem sempre estar formalmente ou juridicamente assim constituído.

De acordo com Marion (2012), encontram-se duas formas jurídicas de exploração: como pessoa física e pessoa jurídica. No Brasil, prevalece a exploração na forma de pessoa física, por ser menos onerosa e mais vantajosa. O pequeno e médio produtor que explora a atividade rural fica dispensado da escrituração comercial, podendo prestar contas por meio da declaração de imposto de renda pessoa física. Já o grande produtor rural será equiparado às pessoas jurídicas para fins contábeis, devendo fazer escrituração regular com profissional contábil habilitado.

\subsection{Ativos Biológicos}

A contabilização da maioria das atividades agropecuárias possui a mesma base conceitual das demais entidades, pois as transações de compra e venda possui a mesma natureza. Porém, a natureza dos seus ativos e a geração de resultados é diferente das demais entidades, tornando o reconhecimento e a mensuração desses ativos com características peculiares não encontradas nas atividades industriais, comerciais e de prestação de serviço (RECH; PEREIRA; OLIVEIRA, 2008).

Desde janeiro de 2010 as demonstrações financeiras das empresas que desempenham atividades envolvendo ativos biológicos e produtos agrícolas devem adotar o CPC 29. O objetivo do CPC 29 (2009) é estabelecer o tratamento contábil, e as respectivas divulgações, relacionadas aos ativos biológicos e aos produtos agrícolas.

Os ativos biológicos são compostos por animais e plantas vivos. Segundo Marion (2012) a contabilidade dos ativos biológicos abrange tudo aquilo que nasce, cresce e morre, desde as culturas temporárias e permanentes até os animais, ou seja, são todos os animais ou plantas vivos.

Segundo Paulo et al. (2011) a emissão do Internacional Accounting Standard 41 - IAS 41, e sua adaptação pelo Pronunciamento Contábil CPC 29, trouxe o preenchimento de uma lacuna existente com relação às regras de mensuração e avaliação de ativos biológicos.

De acordo com Marion (2012), considerando-se que o setor do agronegócio no Brasil é extenso, as mudanças efetuadas causaram um grande impacto na economia. A mudança encontra-se na avaliação dos ativos biológicos, em que o 
modelo tradicional de avaliação pelo custo histórico é substituído pelo valor justo, considerando que esses ativos estão sempre em constantes mudanças, exigindo contínuas avaliações.

Conforme CPC 29 (2009) o ativo biológico deve ser mensurado ao valor justo menos a despesa de venda no momento do reconhecimento inicial e no final de cada período de competência. Para Paulo et al. (2011), com a aplicação obrigatória do CPC 29 as empresas que possuem ativos biológicos passam a registrar as variações provenientes da correção dos preços de mercado desses ativos no momento da apuração de resultados, fato diverso do adotado no custo histórico, que considera o custo de aquisição para registro do valor dos seus estoques de ativos biológicos.

O CPC 29 (2009) evidencia que pode não existir um mercado separado para os ativos, mas pode existir um mercado ativo para a combinação destes, a entidade pode usar informações sobre os ativos combinados para determinar o valor justo dos ativos biológicos.

Para Ernst \& Young e Fipecafi (2010) os critérios de mensuração para os ativos biológicos e para produtos agrícolas são distintos, pois os ativos biológicos devem ser mensurados no seu reconhecimento inicial e em cada data de balanço pelo seu valor justo menos as despesas necessárias para sua venda. No entanto, os produtos agrícolas devem ser mensurados pelo seu valor justo menos as despesas necessárias para a sua venda, mas somente no momento da colheita.

Conforme o CPC 29 (2009, p. 03) "atividade agrícola é o gerenciamento da transformação e da colheita de ativos biológicos para venda ou para conversão em produtos agrícolas ou em ativos biológicos adicionais, pela entidade". Portanto, a atividade agrícola coordena a modificação e/ou o melhoramento de ativos biológicos sujeitos a venda, devendo ser mensurados pelo seu valor justo.

O Quadro 1 apresenta exemplos de ativos biológicos conforme CPC 29 (2009, p. 03):

\section{Quadro 1 - Exemplos de ativos biológicos.}

\begin{tabular}{|l|l|l|}
\hline \multicolumn{1}{|c|}{$\begin{array}{c}\text { Ativos } \\
\text { Biológicos }\end{array}$} & \multicolumn{1}{|c|}{$\begin{array}{c}\text { Produto } \\
\text { agrícola }\end{array}$} & \multicolumn{1}{c|}{$\begin{array}{c}\text { Produtos resultantes do } \\
\text { processamento após a colheita }\end{array}$} \\
\hline Carneiros & Lã & Fio, tapete \\
\hline $\begin{array}{l}\text { Árvores de uma } \\
\text { plantação }\end{array}$ & Madeira & Madeira serrada, celulose \\
\hline Plantas & $\begin{array}{l}\text { Algodão, cana } \\
\text { colhida, café }\end{array}$ & $\begin{array}{l}\text { Fio de algodão, açúcar, álcool, café } \\
\text { limpo em grão, moído, torrado }\end{array}$ \\
\hline Gado de leite & Leite & Queijo \\
\hline Porcos & Carcaça & Salsicha, presunto \\
\hline Arbustos & Folhas & Chá, tabaco \\
\hline Videiras & Uva & Vinho \\
\hline Árvores frutíferas & Fruta colhida & Fruta processada \\
\hline
\end{tabular}

Fonte: CPC 29 (2009, p. 3).

É possível observar no Quadro 01 que os ativos biológicos são todos os animais e plantas vivos. Os produtos resultantes dos ativos biológicos são produtos agrícolas. O terceiro grupo é constituído pelos produtos agro industrializados, resultantes do processo após a colheita e de origem biológica.

Segundo o CPC 29 (2009) a definição da transformação biológica é relevante para se entender a diferença entre ativo biológico e produto agrícola, a diferenciação desses dois itens é relevante para a correta aplicação do 
pronunciamento, pois há possibilidades de mensuração diferentes para os ativos: transformação biológica pressupõe usualmente algo que ainda esteja em transformação ou desenvolvimento, que causam mudanças quantitativas e qualitativas nos ativos biológicos; e produto agrícola corresponde a algo que está pronto para ser colhido de um ativo biológico.

Conforme Marion (2012), o ativo biológico é contabilizado no ativo circulante quando a cultura se desenvolver em curto prazo, ou seja, em tempo menor de 12 meses. Ao contrário, o ativo que exceder a 12 meses, deverá consequentemente ser contabilizado na conta do ativo não circulante, como ocorre com os valores incorridos nas culturas permanentes.

O CPC 29 (2009) não se aplica aos produtos após o processamento ou transformação do produto agrícola, a partir da transformação eles serão tratados de acordo com suas características e passam a serem tratados pelo CPC 16 Estoques.

De acordo com Ernst \& Young e Fipecafi (2010) a entidade deve reconhecer um ativo biológico ou produto agrícola quando: (i) Controla o ativo como resultado de eventos passados; (ii) Quando benefícios econômicos futuros relacionados ao ativo fluírem para a entidade; (iii) $\mathrm{O}$ valor justo ou o custo histórico puder ser mensurado confiavelmente. De acordo com o CPC 29 (2009) os ativos biológicos podem ser classificados conforme demonstrado no Quadro 2.

\section{Quadro 2 - Classificação dos ativos biológicos.}

\begin{tabular}{|l|l|}
\hline \multicolumn{1}{|c|}{ Ativos biológicos } & \multicolumn{1}{c|}{ Características } \\
\hline Consumíveis & $\begin{array}{l}\text { São aqueles passíveis de serem colhidos como produto } \\
\text { agrícola ou vendidos como ativos biológicos. Exemplos: } \\
\text { rebanhos de animais mantidos para a produção de carne, } \\
\text { rebanhos mantidos para a venda, produção de peixe, } \\
\text { plantações de milho, cana-de-açúcar, café, soja, laranja e } \\
\text { trigo e árvores para a produção de madeira. }\end{array}$ \\
\hline Produção & $\begin{array}{l}\text { Não são produtos agrícolas, são autorrenováveis. Exemplo: } \\
\text { rebanhos de animais para a produção de leite, vinhas, } \\
\text { árvores frutíferas, entre outros. }\end{array}$ \\
\hline Maduros & $\begin{array}{l}\text { São aqueles que alcançaram a condição para serem } \\
\text { colhidos. }\end{array}$ \\
\hline Imaturos & São aqueles não aptos para serem colhidos. \\
\hline
\end{tabular}

Fonte: Adaptado de CPC 29 (2009).

A transformação biológica que envolve todo o processo de maturação dos ativos biológicos é o principal fator que distingue os ativos biológicos dos demais ativos, visto que são dotados de vida, sujeitos às mudanças quantitativas e qualitativas.

Contudo, essa transformação biológica e a volatilidade dos preços podem causar ganhos e perdas com esse grupo de ativos, ao longo da maturação. Essa situação pode criar incertezas na determinação dos valores, fazendo com que a base de avaliação seja de fundamental importância no detalhamento das informações.

O CPC 29 (2009) exige o reconhecimento dos ativos biológicos a valor justo aos produtos que possuam mercado ativo. Caso a entidade julgue que não há mercado confiável para fazer essa mensuração, é facultado continuar avaliando seus estoques por meio do custo histórico, até tornar-se possível a mensuração pelo valor justo. Entretanto, a não mensuração a valor justo de um ativo biológico pode 
causar um impacto relevante nas demonstrações financeiras quando esse ativo transformar-se em produto agrícola.

De acordo com Marion (2012), o método do valor justo considera o preço de mercado do plantel que normalmente é maior que o custo, reconhecendo-se um ganho econômico periodicamente. A partir da adoção do CPC 29, animais e plantas vivos devem ser avaliados a valor justo, bem como os produtos agrícolas, com a intenção de repassar aos usuários a real situação patrimonial da atividade desenvolvida.

Segundo o CPC 29 (2009, p. 05):

\begin{abstract}
Valor justo é valor pelo qual um ativo pode ser negociado, ou passivo liquidado, entre partes interessadas, conhecedoras do negócio e independentes entre si, com a ausência de fatores que pressionem para a liquidação da transação ou que caracterizem uma transação compulsória.
\end{abstract}

Silva (2012) reconhece o valor justo como à forma mais coerente e transparente. $O$ autor afirma que por mais que o valor justo esteja errado, ele sempre será inevitavelmente mais próximo da realidade de mercado em relação ao valor do custo histórico.

O valor justo pode vir a ter seu valor alterado devido às mudanças físicas e também pelos preços no mercado. Entretanto as empresas devem sempre procurar mensurar seus ativos biológicos e produtos agrícolas pelo valor justo menos despesas devido à volatilidade.

O método de mensuração a valor justo exige muita cautela quanto à identificação de mercados ativos que admitam a realização da avaliação a valor justo. Pois, de acordo com Marion (2012), ao contrário dos estoques em elaboração das empresas industriais, o gado, a qualquer instante, mesmo sem atingir a semelhança de produtos acabados, tem um preço definido de mercado.

Para Ernst \& Young e Fipecafi (2010) as empresas terão que passar a conviver com a volatilidade inerente aos ativos mensurados ao valor justo. Diretores da área de relação com investidores deverão estar preparados para explicar as oscilações do valor justo que causarão ganhos ou perdas nos resultados, uma explicação não apropriada poderá levantar dúvidas quanto à qualidade dos resultados.

Para Silva Filho, Veras Machado e Reis Machado (2012), o objetivo central da mensuração contábil é estabelecer uma medida que vise aproximar ao máximo a informação contábil à realidade econômica do que se pretende informar, mesmo que o valor justo não seja objetivo e verificável, pode ser o mais relevante para o usuário. O pressuposto é que os valores dos ativos biológicos avaliados a valor justo revelam maior poder preditivo dos ganhos futuros, quando comparados ao custo histórico.

Conforme o CPC 29 (2009) o valor justo de ativo tem sua determinação baseada na localização e nas condições atuais, porém se a entidade tem acesso a diferentes mercados ativos, deve usar o mais relevante deles. Por exemplo, o valor justo do gado é o preço do mercado principal, menos a despesa de transporte e outras despesas necessárias para colocá-lo no referido mercado. Dessa forma, nas contas contábeis o gado destinado à comercialização ficará contabilizado na conta "Ativos Biológicos", no Ativo Circulante, reconhecido pelo seu valor de mercado, enquanto seu ganho econômico fica destacado no resultado.

As empresas que possuem atividades em que 0 ativo biológico se transforma rapidamente em produto agrícola terão seus ganhos ou perdas revertidas 
em poucos meses, devido à similaridade dos valores almejados pelo custo histórico e pelo valor justo.

Entretanto, de acordo com Ernst Young e Fipecafi (2010) a IAS 41 admite a possibilidade de que um ativo biológico ser mensurado ao longo do tempo tanto pelo seu valor de custo histórico, quanto pelo valor justo, tendo em vista situações em que o valor justo não possa ser mensurado de forma confiável ou devido ao estágio de maturação que impossibilita a determinação do valor justo e de um mercado ativo. Contudo, um valor contábil só será relevante quando o mesmo refletir informações confiáveis e sua mensuração for suficientemente adequada, por isso o valor justo torna-se uma medida que visa aproximar as demonstrações contábeis da realidade do mercado.

\subsection{Estudos anteriores}

O estudo de Rech, Pereira e Oliveira (2008) teve como objetivo analisar os efeitos da utilização dos critérios estabelecidos para o reconhecimento e mensuração dos ativos biológicos em relação aos impostos diferidos e verificar o tratamento dispensado a estes ativos e passivos pelas empresas que exploram a atividade rural de pecuária no Estado de Mato Grosso. A amostra da pesquisa foi composta por 21 empresas distribuídas nos diversos municípios do Estado de Mato Grosso. Ao final do estudo verificou-se que apenas parte das empresas pesquisadas utiliza o valor justo para mensurar e reconhecer os ativos biológicos $(23,8 \%)$. Os resultados demonstraram ainda que, embora o critério de tratamento contábil dos impostos diferidos tenha sido introduzido no cenário contábil há mais tempo, somente $28,8 \%$ do total das empresas pesquisadas, e $33,3 \%$ das empresas de pecuária apresentam os impostos diferidos em seu balanço patrimonial e que a mensuração e reconhecimento dos ativos biológicos pelo valor justo impactam o valor dos passivos por impostos diferidos e seu reconhecimento aumenta a transparência nas demonstrações financeiras das empresas.

Medeiros (2009) faz uma análise sobre a Norma de Contabilidade de Relato Financeiro - NCRF 17 versus Plano Oficial de Contabilidade - POC, com enfoque nos Ativos biológicos e produtos agrícolas no ponto de colheita. $\mathrm{O}$ estudo efetuado consistiu na análise dos dois normativos, POC e NCRF 17; na identificação das diferenças comparáveis entre si; e na aplicação da NCRF 17 a uma sociedade agrícola portuguesa, a fim de analisar os efeitos da transição de normativo. Através do estudo verificou-se que a NCRF 17 apresenta consequências significativas na análise às demonstrações financeiras das sociedades agrícolas, derivadas do aumento dos valores do ativo, em contrapartida do aumento dos capitais próprios. $\mathrm{O}$ efeito referido deve-se ao reconhecimento e mensuração dos ativos biológicos e produtos agrícolas (no ponto de colheita) pelo seu justo valor menos os custos estimados no ponto de venda.

Silva Filho, Veras Machado e Reis Machado (2012), em análise da questão do value-relevance dos ativos biológicos mensurados a valor justo e a custo histórico, para dois exercícios diferentes (2008 e 2009), de 25 empresas brasileiras de capital aberto exploradoras de ativos biológicos, demonstram em seus resultados que a substituição do custo histórico pelo valor justo na mensuração dos ativos biológicos não se mostrou relevante para os usuários da informação contábil. Os autores observam o fato de que a mensuração a custo histórico é mais verificável, objetiva e de fácil compreensão, enquanto que a valor justo, geralmente calculado com base em estimativas e probabilidades, a mensuração se torna de difícil entendimento e, consequentemente, pode ser menos relevante para os usuários das informações contábeis. 
Barros et al. (2012) buscaram analisar o impacto do valor justo na mensuração dos ativos biológicos das empresas listadas na BM\&FBOVESPA nos exercícios de 2008 a 2010, através de coleta de dados nos sítios da BM\&FBOVESPA e da CVM. Obtiveram como resultado a revelação de que a média dos valores dos ativos fora crescente em todos os períodos analisados e que foram visualizadas variações significativas após a adoção do valor justo. Concluíram que a aplicação do CPC 29 apresentou impacto na evidenciação contábil das empresas pesquisadas, bem como que as informações sobre os ativos biológicos disponibilizadas nas notas explicativas em geral são superficiais e insuficientes para a compreensão da real situação desses ativos, por não apresentar os critérios utilizados no reconhecimento, mensuração e evidenciação de seus ativos biológicos.

No estudo de Silva Filho, Martins e Machado (2013) o objetivo foi avaliar a relevância da adoção do fair value para mensuração dos ativos biológicos, bem como analisar seus reflexos sobre o patrimônio líquido (PL). Para tanto, analisa-se a questão do value relevance dos ativos biológicos mensurados ao custo histórico e ao fair value, bem como o impacto da mudança de base de mensuração sobre o PL, para os exercícios de 2008 e 2009, das empresas listadas na BM\&FBovespa, que exploram tais ativos. As evidências empíricas encontradas apontam que a adoção do valor justo causou mudanças significativas no saldo dos ativos biológicos, que por sua vez impactou, significativamente, o PL das companhias. As evidências sugerem ainda que os ativos biológicos, quando avaliados pelo custo histórico, eram apresentados com valores subestimados pela contabilidade. Portanto, a avaliação pelo valor justo foi benéfica, uma vez que se apresentou mais próxima da estimação do mercado. Uma justificativa plausível para esse achado é o fato de que com o passar do tempo, o custo histórico é suscetível de não refletir a capacidade de benefício econômico do bem, uma vez que se limita aos valores de face na data da aquisição ou produção.

\section{METODOLOGIA}

O estudo delimitou-se a evidenciar a mensuração contábil da atividade leiteira comparando os critérios de avaliação pelo custo histórico e pelo valor justo dos ativos biológicos, de uma propriedade rural localizada no Oeste Catarinense.

O período de análise da atividade leiteira se refere aos meses de julho e agosto de 2013, foram consideradas nestes períodos as culturas temporárias que agregam custos a atividade, tais como o milho para silagem, as pastagens temporárias e permanentes.

A pesquisa possui caráter de cunho exploratório, realizada por meio de um estudo de caso, com análise de cunho qualitativo para a abordagem do problema e mensuração dos resultados. A coleta de dados foi realizada por meio de entrevistas informais, visitas e documentos. Foi necessário realizar o levantamento dos dados patrimoniais e documentos (custos, receitas e despesas) para proceder à elaboração do DRE e BP da entidade. Posteriormente, com a apuração dos resultados pelo custo histórico foi possível verificar as variações contábeis entre o custo histórico e o valor justo dos ativos biológicos da entidade rural estudada.

O ambiente do estudo está localizado no município de Quilombo/SC, na comunidade São Ricardo. A família Pazinatto, reside na propriedade rural desde 1969 , tendo inicialmente como atividade principal a criação de suínos. No entanto com o passar dos anos, devido às deficiências na rentabilidade, ela foi sendo descontinuada. A partir de 1995, o produtor substituiu a suinocultura pela bovinocultura leiteira. No desenvolvimento da atividade leiteira o proprietário rural é responsável pelo trato das matrizes no pasto, organizar as pastagens em piquetes, 
alimentação dos animais e o preparo da silagem; sua esposa é responsável pela ordenha e a limpeza do estábulo.

Os dados coletados nesta pesquisa foram tratados por meio da análise documental, a qual permite descobrir circunstâncias sociais e econômicas; buscar informações factuais com técnica exploratória em documentos, tais como notas fiscais, recibos e anotações realizadas pelo gestor. Foram elaboradas tabelas para identificar os custos da atividade leiteira, a demonstração do resultado, o balanço patrimonial e o comparativo entre custo histórico e valor justo.

Para a utilização do valor justo aos ativos biológicos da entidade, buscou-se identificar o valor de mercado ativo destes itens, considerando-se sua condição no momento da análise. Por meio de um provável comprador, identificou-se o valor de venda destes animais, classificados no ativo circulante e no ativo imobilizado como ativos biológicos.

A principal limitação da pesquisa se refere à falta de todos os documentos hábeis comprobatórios das informações obtidas para o desenvolvimento do estudo, o qual foi realizado com base em dados e anotações prestadas informalmente por meio de questionamentos ao gestor da entidade rural pesquisada.

Os resultados do estudo permitem a identificação do resultado da atividade leiteira no período analisado, apurado por meio de valores históricos, bem como possibilita comparar a valorização patrimonial quando utilizado os critérios de análise pelo valor justo, conforme orienta a normativa contábil CPC 29.

\section{ANÁLISE DOS DADOS}

A partir dos dados coletados iniciou-se o processo de análise dos resultados. O Quadro 03 demonstra inicialmente o funcionamento e etapas do processo de ordenha.

\section{Quadro 3 - Processo de ordenha.}

\begin{tabular}{|l|l|}
\hline 1 & As matrizes leiteiras são transferidas da sala de espera para a sala de ordenha. \\
\hline 2 & A água é aquecida para realização da limpeza das matrizes. \\
\hline 3 & $\begin{array}{l}\text { Devido à aquisição de três conjuntos de teteiras são ordenhadas } 03 \text { matrizes } \\
\text { por vez. }\end{array}$ \\
\hline 4 & $\begin{array}{l}\text { Conforme as vacas vão sendo ordenhadas o medidor informa o esgotamento } \\
\text { do leite. }\end{array}$ \\
\hline 5 & O leite é transferido diretamente para o resfriador (capacidade de 1.000 litros). \\
\hline 6 & $\begin{array}{l}\text { Após o esgotamento do leite dessas três matrizes leiteiras, elas são } \\
\text { transferidas para sala de trato e assim sucessivamente, enquanto o leite } \\
\text { aguarda a coleta pela empresa responsável. As matrizes são ordenhadas duas } \\
\text { vezes ao dia, pela parte da manhã e ao final do dia. }\end{array}$ \\
\hline
\end{tabular}

Fonte: Elaborado pelos autores com dados da pesquisa.

O produtor utiliza-se de um sistema de controle diário da quantidade de litros vendidos e de produção de leite, visando comparar com os valores pagos pela cooperativa a partir da quantidade de leite coletado. Atualmente a atividade leiteira é a única atividade desempenhada na propriedade rural, portanto, todas as receitas geradas devem ser capazes de satisfazer todas as despesas e custos do processo leiteiro, além de gerar resultados para prover as necessidades da família. 


\subsection{Inventário}

O período de realização da pesquisa e levantamento dos dados refere-se aos meses de julho/2013 e agosto/2013. As instalações são compostas por um estábulo de $8 \times 23$ metros (sala de ordenha e sala de trato) onde realiza-se a ordenha das matrizes leiteira e consequentemente sua alimentação, com capacidade para 27 animais. Para realização do transporte da silagem e auxílio do trabalho, o produtor rural possui um trator, ano 1979, seminovo, adquirido em 2009, com valor de custo histórico de $\mathrm{R} \$ 15.000,00$ e vida útil de 10 anos. O trator é manuseado uma hora por dia, ou seja, trinta horas mensais tendo um gasto com combustível de $R \$ 207,00$ mensais. Na Tabela 1 apresenta-se a depreciação do imobilizado.

Tabela 4 - Identificação dos itens imobilizados.

\begin{tabular}{|c|c|c|c|c|c|c|c|c|}
\hline $\begin{array}{l}\text { Imobili- } \\
\text { zado }\end{array}$ & Un. & $\begin{array}{l}\text { Valor de a- } \\
\text { quisição } \\
\text { (R\$) }\end{array}$ & $\begin{array}{l}\text { Valor } \\
\text { residual } \\
(\mathbf{R} \$)\end{array}$ & $\begin{array}{l}\text { Base para } \\
\text { depreciar } \\
(\mathrm{R} \$)\end{array}$ & $\begin{array}{c}\text { Vida } \\
\text { útil } \\
\text { (anos) }\end{array}$ & $\begin{array}{l}\text { Aqui- } \\
\text { sição } \\
\text { (ano) }\end{array}$ & $\begin{array}{c}\text { Deprec. } \\
\text { mensal } \\
\text { (R\$) }\end{array}$ & $\begin{array}{c}\text { Deprec. } \\
\text { acum. } \\
\text { (R\$) }\end{array}$ \\
\hline $\begin{array}{l}\text { Estábulo } \\
\text { Resfriador }\end{array}$ & $\begin{array}{l}1 \\
1\end{array}$ & $\begin{array}{l}25.000, \\
13.000,\end{array}$ & $\begin{array}{l}6.000 \\
5.000\end{array}$ & $\begin{array}{c}19.000 \\
8.000\end{array}$ & $\begin{array}{l}20 \\
10\end{array}$ & $\begin{array}{l}2009 \\
2009\end{array}$ & $\begin{array}{l}79,17 \\
66,67\end{array}$ & $\begin{array}{l}4.433, \\
3.733\end{array}$ \\
\hline $\begin{array}{l}\text { Iranste- } \\
\text { ridor }\end{array}$ & 1 & 2.800, & 500 & 2.300, & 12 & 2008 & 15,97 & 1.085 \\
\hline $\begin{array}{l}\text { Conjunto } \\
\text { de teteiras }\end{array}$ & 3 & 2.700, & 500 & 2.200, & 12 & 2007 & 15,28 & 1.222 \\
\hline $\begin{array}{l}\text { Aquecedor } \\
\text { Medidor }\end{array}$ & $\begin{array}{l}1 \\
3\end{array}$ & $\begin{array}{l}2000, \\
3.000,\end{array}$ & $\begin{array}{l}400 \\
600\end{array}$ & $\begin{array}{l}1.600 \\
2.400\end{array}$ & $\begin{array}{c}12 \\
8\end{array}$ & $\begin{array}{l}2011 \\
2011\end{array}$ & $\begin{array}{l}11,11 \\
25,00\end{array}$ & $\begin{array}{l}355 \\
800\end{array}$ \\
\hline Trator & 1 & 15.000, & 7.000, & 8.000 & 10 & 2009 & 66,67 & 3.733 \\
\hline Total & - & 63.500, & 20.000 & 43.500, & - & - & 279,87 & 15.364 \\
\hline
\end{tabular}

Fonte: Dados da pesquisa.

$\mathrm{Na}$ Tabela 1, observa-se a composição do imobilizado, a depreciação mensal de $R \$ 279,87$ e a depreciação acumulada de $R \$ 15.364,00$, referente aos bens adquiridos pelo produtor para o desenvolvimento da atividade leiteira. A Tabela 2 evidencia o levantamento patrimonial das matrizes leiteiras. 
Tabela 5 - Depreciação das matrizes.

\begin{tabular}{cccccccr}
\hline $\begin{array}{c}\text { Código } \\
\text { matrizes }\end{array}$ & Idade & $\begin{array}{c}\text { Valteira } \\
\text { histórico } \\
\text { (R\$) }\end{array}$ & $\begin{array}{c}\text { Valor } \\
\text { residual } \\
\text { (R\$) }\end{array}$ & $\begin{array}{c}\text { Base p/ } \\
\text { depreciar } \\
\text { (R\$) }\end{array}$ & $\begin{array}{c}\text { Vida } \\
\text { útil } \\
\text { (anos) }\end{array}$ & $\begin{array}{c}\text { Deprec. } \\
\text { mensal } \\
\text { (R\$) }\end{array}$ & $\begin{array}{c}\text { Deprec. } \\
\text { acumulada } \\
\text { (R\$) }\end{array}$ \\
\hline 000639 & 1 & $6.000,00$ & $1.700,00$ & $4.300,00$ & 8 & 44,79 & 537,50 \\
000640 & 1 & $6.000,00$ & $1.700,00$ & $4.300,00$ & 8 & 44,79 & 537,50 \\
004717 & 1 & $6.000,00$ & $1.700,00$ & $4.300,00$ & 8 & 44,79 & 537,50 \\
004719 & 1 & $6.000,00$ & $1.700,00$ & $4.300,00$ & 8 & 44,79 & 537,50 \\
010398 & 3 & $4.000,00$ & $1.700,00$ & $2.300,00$ & 8 & 23,96 & 862,50 \\
086831 & 1 & $6.000,00$ & $1.700,00$ & $4.300,00$ & 8 & 44,79 & 537,50 \\
112067 & 2 & $4.500,00$ & $1.700,00$ & $2.800,00$ & 8 & 29,17 & 700,00 \\
137429 & 2 & $4.500,00$ & $1.700,00$ & $2.800,00$ & 8 & 29,17 & 700,00 \\
375953 & 2 & $4.500,00$ & $1.700,00$ & $2.800,00$ & 8 & 29,17 & 700,00 \\
431343 & 2 & $4.500,00$ & $1.700,00$ & $2.800,00$ & 8 & 29,17 & 700,00 \\
459746 & 3 & $4.000,00$ & $1.700,00$ & $2.300,00$ & 8 & 23,96 & 862,50 \\
478465 & 5 & $3.500,00$ & $1.700,00$ & $1.800,00$ & 8 & 18,75 & $1.125,00$ \\
493845 & 5 & $3.500,00$ & $1.700,00$ & $1.800,00$ & 8 & 18,75 & $1.125,00$ \\
493863 & 4 & $4.000,00$ & $1.700,00$ & $2.300,00$ & 8 & 23,96 & $1.150,00$ \\
493866 & 4 & $4.000,00$ & $1.700,00$ & $2.300,00$ & 8 & 23,96 & $1.150,00$ \\
752666 & 2 & $4.500,00$ & $1.700,00$ & $2.800,00$ & 8 & 29,17 & 700,00 \\
852651 & 3 & $4.000,00$ & $1.700,00$ & $2.300,00$ & 8 & 23,96 & 862,50 \\
852654 & 2 & $4.500,00$ & $1.700,00$ & $2.800,00$ & 8 & 29,17 & 700,00 \\
873015 & 8 & $3.500,00$ & $1.700,00$ & $1.800,00$ & 8 & 18,75 & $1.800,00$ \\
876857 & 4 & $4.000,00$ & $1.700,00$ & $2.300,00$ & 8 & 23,96 & $1.150,00$ \\
876898 & 7 & $3.500,00$ & $1.700,00$ & $1.800,00$ & 8 & 18,75 & $1.575,00$ \\
968649 & 2 & $4.500,00$ & $1.700,00$ & $2.800,00$ & 8 & 29,17 & 700,00 \\
968650 & 2 & $4.500,00$ & $1.700,00$ & $2.800,00$ & 8 & 29,17 & 700,00 \\
Total & - & $\mathbf{1 0 4 . 0 0 0 , 0 0}$ & $\mathbf{3 9 . 1 0 0 , 0 0}$ & $\mathbf{6 4 . 9 0 0 , 0 0}$ & $\mathbf{8}$ & $\mathbf{6 7 6 , 0 7}$ & $\mathbf{1 9 . 9 5 0 , 0 0}$ \\
\hline
\end{tabular}

Fonte: Dados da pesquisa.

As informações da Tabela 2 demonstram a depreciação mensal e acumulada de cada uma das 23 matrizes mantidas na propriedade, conforme seu valor histórico, seu valor residual e a vida útil, devidamente relacionado com a numeração fornecida pela Companhia Integrada de Desenvolvimento Agrícola de Santa Catarina (CIDASC). O estabelecimento é composto por 23 matrizes, todas de raça holandesa pura, o valor de custo histórico unitário varia entre $R \$ 3.500,00$ a $R \$$ $6.000,00$ por animal, totalizando $R \$ 104.000,00$. O valor residual médio de cada matriz é de $R \$ 1.700,00$ (valor de venda ao final da vida útil esperada) e a vida útil das mesmas é de 8 anos, ou 8 crias.

A propriedade rural estudada possui 59 hectares, com valor de $R \$$ $15.000,00$ por hectare, utilizados na plantação de milho, pastagens, reflorestamento e para a pastagem dos bovinos. A alimentação dos animais é feita com silagem, pastagem permanente (grama) e pastagem temporária (aveia de inverno, aveia de verão ou azevém) além de alguns concentrados (minerais). Nas áreas planas da propriedade rural são cultivadas as culturas de milho, sorgo, aveia e azevém.

A pastagem utilizada nos períodos de realização da pesquisa foi o azevém titan uruguaio, com plantio foi efetuado em 2,5 hectares em abril/2013 e o consumo a partir de julho/2013, com durabilidade prevista até dezembro/2013. Na Tabela 3 são apresentados os gastos para a realização do plantio do azevém: 
Tabela 6 - Custo do azevém.

\begin{tabular}{lccc}
\hline \multicolumn{1}{c}{ Produto } & Quantidade & Valor unitário (R\$) & Valor Total (R\$) \\
\hline Secante & $10,9 \mathrm{lt}$ & $11,00 / \mathrm{lt}$ & 120,00 \\
Semente & $132,35 \mathrm{~kg}$ & $6,80 / \mathrm{kg}$ & 900,00 \\
Adubo & $750 \mathrm{~kg}$ & $1,64 / \mathrm{kg}$ & $1.230,00$ \\
Inseticida & $1 \mathrm{lt}$ & $55,00 / \mathrm{lt}$ & 55,00 \\
Manutenção & $6,38 \mathrm{~h}$ & $65,00 / \mathrm{h}$ & 415,00 \\
Total & $\mathbf{8 0 . 0 0 0 ~} \mathbf{~ k g}$ & $\mathbf{0 , 0 3}$ & $\mathbf{2 . 7 2 0 , 0 0}$ \\
\hline
\end{tabular}

Fonte: Dados da pesquisa.

$\mathrm{Na}$ Tabela 3 são evidenciados os gastos necessários para o plantio do azevém, totalizando $\mathrm{R} \$ 2.720,00$ correspondentes aos $80.000 \mathrm{~kg}$ cultivados nos 2,5 hectares. Outro produto desenvolvido na propriedade rural, para alimentar o gado leiteiro é a silagem, plantada em setembro/2012 e colhida em janeiro/2013, a silagem somente começou a ser utilizada em fevereiro/2013, com durabilidade prevista até novembro/2013. Os gastos referentes à silagem são equivalentes aos 5,5 hectares cultivados, conforme apresenta a Tabela 4.

\begin{tabular}{lccc}
\multicolumn{1}{l}{ Tabela 7 - Custo da silagem. } \\
\hline Produto & Quantidade & Valor unitário (R\$) & Valor Total \\
\hline Milho & $120 \mathrm{~kg}$ & $16,96 / \mathrm{kg}$ & $2.035,00$ \\
Adubo & $1.650 \mathrm{~kg}$ & $1,98 / \mathrm{kg}$ & $3.276,00$ \\
Uréia & $1.650 \mathrm{~kg}$ & $1,00 / \mathrm{kg}$ & $1.650,00$ \\
Inseticida & $2 \mathrm{It}$ & $55,00 / \mathrm{lt}$ & 110,00 \\
Manutenção & $40,52 \mathrm{~h}$ & $65,00 / \mathrm{h}$ & $2.634,00$ \\
Mão de obra & - & - & 600,00 \\
Material & - & - & $1.798,00$ \\
Plantio & - & - & 550,00 \\
Total & $\mathbf{2 0 4 . 0 0 0 ~ k g}$ & $\mathbf{0 , 0 6}$ & $\mathbf{1 2 . 6 5 3 , 0 0}$ \\
\hline
\end{tabular}

Fonte: Dados da pesquisa.

$\mathrm{Na}$ Tabela 4 observa-se o custo da silagem de $R \$ 12.653,00$, equivalente aos $204.000 \mathrm{~kg}$ cultivados nos 5,5 hectares. O valor médio de custo mensal de silagem é de $R \$ 1.263,00$, considerando a expectativa de 10 meses de consumo.

Para o desempenho da atividade leiteira alguns gastos são necessários para seu desenvolvimento e manutenção. A Tabela 5 indica os gastos mensais com as matrizes nos períodos de julho/2013 e agosto/2013. 
Tabela 8 - Custo do leite.

\begin{tabular}{|c|c|c|c|c|c|}
\hline \multirow[b]{2}{*}{ Produtos } & \multirow{2}{*}{$\begin{array}{c}\text { Quantida- } \\
\text { de diária } \\
(\mathrm{kg})\end{array}$} & \multirow{2}{*}{$\begin{array}{l}\text { Preço } \\
\text { unitá- } \\
\text { rio (R\$) }\end{array}$} & \multirow{2}{*}{$\begin{array}{c}\text { Quantida- } \\
\text { de mensal } \\
(\mathrm{kg})\end{array}$} & \multicolumn{2}{|c|}{ Valor total (R\$) } \\
\hline & & & & Julho & Agosto \\
\hline Silagem & 600 & 0,06 & 18.000 & $1.080,00$ & $1.080,00$ \\
\hline Ração & 184 & 0,77 & 5.520 & $4.250,40$ & $4.250,40$ \\
\hline $\begin{array}{l}\text { Concentrados } \\
\text { (minerais) }\end{array}$ & 6,90 & 2,39 & 207 & 495,00 & 495,00 \\
\hline Azevém Titan & 445 & 0,03 & 13.350 & 400,50 & 400,50 \\
\hline Medicamentos & - & - & - & 418,00 & 400,00 \\
\hline $\begin{array}{l}\text { Serviços com } \\
\text { trator }\end{array}$ & - & - & - & 136,03 & 136,03 \\
\hline $\begin{array}{l}\text { Deprec. dos } \\
\text { equipamentos }\end{array}$ & - & - & - & 279,87 & 279,87 \\
\hline $\begin{array}{l}\text { Deprec. das } \\
\text { matrizes }\end{array}$ & - & - & - & 676,07 & 676,07 \\
\hline Energia elétrica & - & - & - & 150,00 & 150,00 \\
\hline Manutenção & - & - & - & 227,00 & 0,00 \\
\hline $\begin{array}{l}\text { Produtos de } \\
\text { limpeza }\end{array}$ & - & - & - & 166,40 & 111,38 \\
\hline Total & - & - & - & $8.279,27$ & $7.979,25$ \\
\hline
\end{tabular}

Fonte: Dados da pesquisa.

A Tabela 5 indica o custo mensal da atividade leiteira nos períodos de julho e agosto, totalizando $R \$ 8.279,27$ e $R \$ 7.979,25$ respectivamente. A água consumida pelos animais é oriunda de um reservatório próprio, não gerando custos adicionais. Quanto à energia elétrica, manutenção, medicamentos, produtos de limpeza são gastos da atividade conforme já demonstrado na Tabela 5.

A mão de obra é desenvolvida pelos proprietários que não possuem salário fixo, e por não haver desembolso não foram considerados, neste caso precisa-se salientar que os resultados devem ser capazes de gerar tal remuneração. A propriedade rural possui 13 bezerras (até 6 meses) que equivalem a $R \$ 3.500,00$ cada uma, totalizando $R \$ 45.500,00$, e 12 novilhas em processo de formação (de 7 a 18 meses), equivalente a $R \$ 6.500,00$ cada uma delas, totalizando $R \$ 78.000,00$. Considerando que as novilhas ainda não se tornaram matrizes, não foi constituída a respectiva depreciação. O cálculo da depreciação somente começa a ser realizado após a primeira cria. Nas Tabelas 6 e 7, observam-se os gastos mensais com as bezerras e novilhas.

Tabela 9 - Custo mensal das bezerras.

\begin{tabular}{lcccr}
\hline \multicolumn{1}{c}{ Insumos } & $\begin{array}{c}\text { Quantidade } \\
\text { diária (I/kg) }\end{array}$ & $\begin{array}{c}\text { Preço } \\
\text { unitário (R\$) }\end{array}$ & $\begin{array}{c}\text { Quantidade } \\
\text { mensal (I/kg) }\end{array}$ & $\begin{array}{r}\text { Valor total } \\
\text { (R\$) }\end{array}$ \\
\hline Leite & 52 & 1,05 & $1.560,00$ & $1.638,00$ \\
Granulado & 6 & 1,87 & 180 & 336,60 \\
Remédios & - & - & - & 7,68 \\
Saldo & - & - & - & $\mathbf{1 . 9 8 2 , 2 8}$ \\
\hline
\end{tabular}

Fonte: Dados da pesquisa.

A Tabela 6 evidencia o gasto mensal de $R \$ 1.982,28$, referente à criação das 13 bezerras. Porém, como o período das bezerras é equivalente a 6 meses até 
tornarem-se novilhas, os gastos com as mesmas foram de $R \$ 11.893,68$ e o gasto unitário no período foi de $\mathrm{R} \$ 914,90$.

Tabela 10 - Custo mensal das novilhas.

\begin{tabular}{lcccc}
\hline \multicolumn{1}{c}{ Insumos } & $\begin{array}{c}\text { Quantidade } \\
\text { diária (/kg) }\end{array}$ & $\begin{array}{c}\text { Preço } \\
\text { unitário (R\$) }\end{array}$ & $\begin{array}{c}\text { Quantidade } \\
\text { mensal (/kg) }\end{array}$ & $\begin{array}{c}\text { Valor total } \\
\text { (R\$) }\end{array}$ \\
\hline Silagem & 80 & 0,06 & 2.400 & 144,00 \\
Ração & 12 & 0,77 & 360 & 277,20 \\
Concentrados & 3 & 2,40 & 90 & 216,00 \\
(minerais) & 16 & 0,35 & 480 & 168,00 \\
Feno & - & - & - & 80,00 \\
Medicamentos & - & - & - & 70,97 \\
Serviços c/ trator & - & - & - & $\mathbf{9 5 6 , 1 7}$ \\
\multicolumn{1}{r}{ Saldo } & & & &
\end{tabular}

Fonte: Dados da pesquisa.

Conforme a Tabela 7, o gasto mensal com as 12 novilhas é de $R \$ 956,17$. Como o período de crescimento e maturação das novilhas é de 12 meses (do $7^{\circ}$ ao 18ํㅡês), foram gastos com as mesmas um total de $\mathrm{R} \$ 11.474,04$ no período.

Tabela 11 - Novilhas e bezerras.

\begin{tabular}{ccccc}
\hline Tipo & $\begin{array}{c}\text { Idade } \\
\text { (meses) }\end{array}$ & Quantidade & $\begin{array}{c}\text { Custo histórico } \\
\text { unitário (R\$) }\end{array}$ & $\begin{array}{c}\text { Valor justo } \\
\text { unitário (R\$) }\end{array}$ \\
\hline Bezerras & 3 a 5 & 13 & 914,90 & $3.500,00$ \\
Novilhas & 8 a 13 & 12 & $1.871,07$ & $6.500,00$ \\
\hline
\end{tabular}

Fonte: Dados da pesquisa.

Conforme a Tabela 8, o custo histórico unitário das bezerras de $\mathrm{R} \$ 914,90$ equivale a todo o período (até 6 meses) e o custo histórico das novilhas de $R \$$ 956,17 equivale aos 12 meses (dos 7 aos 18 meses). Portanto, o custo histórico de uma novilha, referente a todo seu processo de crescimento até os 18 meses totalizou em média $\mathrm{R} \$ 1.871,07$.

Para identificar o valor justo das bezerras e novilhas, questionou-se um provável comprador de animais destinados à atividade leiteira, que considera a raça, o porte e características físicas dos animais, Neste caso, a avaliação realizada estimada para as bezerras com até 6 meses de idade foi de $R \$ 3.500,00$ cada, e para as novilhas de $\mathrm{R} \$ 6.500,00$ cada. Estes valores são, portanto, os valores justos que nesta condição são iguais aos valores de mercado ativo. Atualmente, a bovinocultura de leite e a venda das novilhas são as únicas atividades desempenhadas na propriedade, portanto todas as receitas geradas por essas devem ser capazes de satisfazer todas as necessidades provindas da família e consequentemente as despesas e custos do processo leiteiro. A plantação de pastagens desenvolvidas na propriedade e os cuidados com a mesma são de uso exclusivo da bovinocultura leiteira e a criação das novilhas.

Em média, são vendidas 08 novilhas por ano e quando eventualmente um animal morre a perda torna-se contabilmente adicionada aos custos do período.

Analisando os períodos de julho e agosto, constatou-se uma produção leiteira no mês de julho de 21.500 litros de leite e no mês de agosto de 19.800 litros, os quais foram vendidos a $R \$ 1,05$ ao litro (preço de venda já descontado o Funrural de $2,3 \%$ sobre nota fiscal). O leite é vendido para uma cooperativa, que realiza o recolhimento do leite diariamente e assume as despesas com o transporte do 
caminhão, combustível, mão de obra e manutenção, despesas essas desconsideradas pelo produtor.

Na Demonstração do Resultado do Exercício, apresentada na Tabela 9, destaca-se o resultado mensal dos períodos de julho e agosto correspondentes ao desenvolvimento e manutenção da atividade leiteira, recapitulando assim, todos os gastos destacados no decorrer desta análise e a avaliação horizontal percentual dos dados obtidos.

Tabela 12 - Demonstração de Resultado do Exercício.

\begin{tabular}{lrrrr}
\hline & $\begin{array}{c}\text { Julho/2013 } \\
\text { (R\$) }\end{array}$ & \multicolumn{1}{c}{$\begin{array}{c}\text { Agosto/20 } \\
\mathbf{1 3}(\mathbf{R} \mathbf{\$})\end{array}$} & \multicolumn{1}{c}{$\%$} \\
\hline (+) Receita líquida com vendas & $\mathbf{2 2 . 5 7 5 , 0 0}$ & $\mathbf{1 0 0}$ & $\mathbf{2 0 . 7 9 0 , 0 0}$ & $\mathbf{1 0 0}$ \\
- Leite & $22.575,00$ & 100 & $20.790,00$ & 100 \\
(-) Custo do leite vendido & $(\mathbf{8 . 2 7 9 , 2 7 )}$ & $\mathbf{3 6 , 6 7}$ & $(\mathbf{7 . 9 7 9 , 2 5 )}$ & $\mathbf{3 8 , 3 8}$ \\
- Alimentação & $(6.225,90)$ & 27,58 & $(6.225,90)$ & 29,95 \\
- Depreciação & $(955,94)$ & 4,23 & $(955,94)$ & 4,60 \\
- Luz & $(150,00)$ & 0,66 & $(150,00)$ & 0,72 \\
- Manutenção & $(227,00)$ & 1,01 & 0,00 & - \\
- Medicamento & $(418,00)$ & 1,85 & $(400,00)$ & 1,92 \\
- Produtos limpeza & $(166,40)$ & 0,74 & $(111,38)$ & 0,54 \\
- Serviços trator & $(136,03)$ & 0,60 & $(136,03)$ & 0,65 \\
(=) Lucro Bruto & $\mathbf{1 4 . 2 9 5 , 7 3}$ & $\mathbf{6 3 , 3 3}$ & $\mathbf{1 2 . 8 1 0 , 7 5}$ & $\mathbf{6 1 , 6 2}$ \\
(+) Outras Receitas Operacionais & $\mathbf{3 2 . 5 0 0 , 0 0}$ & $\mathbf{1 4 3 , 9 6}$ & $\mathbf{0 , 0 0}$ & - \\
- Venda matrizes & $26.000,00$ & 115,17 & 0,00 & - \\
- Venda novilhas & $6.500,00$ & 28,79 & 0,00 & - \\
(-) Outras Despesas Operacionais & $\mathbf{( 1 . 8 7 1 , 0 7 )}$ & $\mathbf{8 , 2 9}$ & $\mathbf{0 , 0 0}$ & - \\
- Custo das novilhas vendidas & $\mathbf{( 1 . 8 7 1 , 0 7 )}$ & $\mathbf{8 , 2 9}$ & $\mathbf{0 , 0 0}$ & - \\
(=) Resultado do Exercício & $\mathbf{4 4 . 9 2 4 , 6 6}$ & $\mathbf{1 9 9}$ & $\mathbf{1 2 . 8 1 0 , 7 5}$ & $\mathbf{6 1 , 6 2}$ \\
Quantidade leite vendida (L) & $\mathbf{2 1 . 5 0 0 , 0 0}$ & - & $\mathbf{1 9 . 8 0 0 , 0 0}$ & - \\
Receita por litro de leite & $\mathbf{1 , 0 5}$ & - & $\mathbf{1 , 0 5}$ & - \\
Custo por litro vendido & $\mathbf{0 , 3 9}$ & - & $\mathbf{0 , 4 0}$ & - \\
Lucro por litro vendido & $\mathbf{0 , 6 6}$ & - & $\mathbf{0 , 6 5}$ & - \\
\hline
\end{tabular}

Fonte: Dados da pesquisa.

A Tabela 9 demonstra as receitas, os custos, despesas e sucessivamente o resultado correspondente ao exercício da atividade leiteira. O período de julho apresentou um lucro de $R \$ 14.295,73$ devido à venda de 21.500 litros de leite e em agosto o lucro foi de $R \$ 12.810,75$ referentes à venda de 19.800 litros de leite. Considerando-se a venda das matrizes e das novilhas no mês de julho, o resultado deste período foi de $R \$ 44.924,66$. A receita líquida por litro de leite vendido em julho e agosto foi de $R \$ 1,05$. O custo por litro de leite vendido em julho foi de $R \$$ 0,39 e em agosto foi de $R \$ 0,40$. O lucro por litro de leite em julho foi de $R \$ 0,66$ e em agosto foi de $R \$ 0,65$, portanto, em julho a atividade apresentou um lucro de 0,01 por litro a mais do que em agosto. A margem líquida da atividade leiteira foi de $63,33 \%$ em julho e $61,62 \%$ em agosto, no entanto salienta-se que este resultado precisa remunerar a mão de obra dos gestores.

$\mathrm{Na}$ Tabela 10 apresenta-se o Balanço Patrimonial evidenciando a posição patrimonial e financeira da entidade após o levantamento realizado. 
Tabela 13 - Balanço Patrimonial.

\begin{tabular}{|c|c|c|}
\hline ATIVO & $\begin{array}{c}\text { Valor histórico } \\
(R \$)\end{array}$ & Valor justo (R\$) \\
\hline Ativo Circulante & $29.371,72$ & $129.504,00$ \\
\hline Caixa e equivalentes de caixa & - & - \\
\hline Estoque & $4.085,00$ & $4.085,00$ \\
\hline Produto agrícola - silagem & $4.085,00$ & $4.085,00$ \\
\hline Ativos Biológicos & $25.286,72$ & $125.419,00$ \\
\hline Pastagem temporária - azevém & $1.919,00$ & $1.919,00$ \\
\hline Bezerras em formação & $11.893,68$ & $45.500,00$ \\
\hline Novilhas em formação & $11.474,04$ & $78.000,00$ \\
\hline Ativo não circulante & $1.080 .685,56$ & $1.146 .135,56$ \\
\hline Imobilizado & $996.635,56$ & $996.635,56$ \\
\hline Terreno & $885.000,00$ & $885.000,00$ \\
\hline Benfeitorias & $50.000,00$ & $50.000,00$ \\
\hline Máquinas e equipamentos & $63.500,00$ & $63.500,00$ \\
\hline - Aquecedor & $2.000,00$ & $2.000,00$ \\
\hline - Conjunto teteiras & $2.700,00$ & $2.700,00$ \\
\hline - Estábulo & $25.000,00$ & $25.000,00$ \\
\hline - Medidor & $3.000,00$ & $3.000,00$ \\
\hline - Resfriador & $13.000,00$ & $13.000,00$ \\
\hline - Transferidor & $2.800,00$ & $2.800,00$ \\
\hline - Trator & $15.000,00$ & $15.000,00$ \\
\hline (-) Depreciações acumuladas & $(55.364,44)$ & $(55.364,44)$ \\
\hline Ativos Biológicos & $84.050,00$ & $149.500,00$ \\
\hline Matrizes leiteiras & $104.000,00$ & $149.500,00$ \\
\hline (-) Depreciação acumulada matrizes & $(19.950,00)$ & \\
\hline $\begin{array}{l}\text { TOTAL ATIVO } \\
\text { PASSIVO }\end{array}$ & $1.110 .057,28$ & $1.275 .639,56$ \\
\hline Passivo circulante & - & - \\
\hline Passivo não circulante & - & - \\
\hline Patrimônio líquido & $1.110 .057,28$ & $1.275 .639,56$ \\
\hline Capital Social & $1.052 .321,87$ & $1.052 .321,87$ \\
\hline - Capital Integralizado & 1.052 .321 .87 & 1.052 .321 .87 \\
\hline Ajuste de avaliação patrimonial & - & $165.582,28$ \\
\hline Lucro ou prejuízo do exercício & $57.735,41$ & $57.735,41$ \\
\hline - Lucro do exercício & $57.735,41$ & $57.735,41$ \\
\hline TOTAL PASSIVO & 1.110 .057 .28 & 1.275 .639 .56 \\
\hline
\end{tabular}

Fonte: Dados da pesquisa.

A venda decorrente das matrizes, novilhas e bezerras avaliadas pelo seu valor justo, é negociada entre produtores que praticam a mesma atividade. As matrizes leiteiras negociadas são vendidas por aproximadamente $R \$ 6.500,00$.

Analisando-se a situação financeira da propriedade rural estudada e os resultados apresentados no Balanço Patrimonial do período, observa-se que o valor do saldo final do ativo e passivo se avaliados pelo método do custo histórico totalizam $R \$ 1.110 .057,28$ e se avaliados pelo valor justo totalizam $R \$ 1.275 .639,56$.

A identificação dos itens que estão dispostos no Balanço Patrimonial foi realizada anteriormente na análise das Tabelas 1, 2 e 3, incluso o valor das benfeitorias na Tabela 10 (cercas e um galpão que serve de depósito de insumos, os quais possuem mais de 20 anos de uso). Embora já se encontrem totalmente depreciados fazem parte do patrimônio da entidade. 
A diferença positiva provocada no saldo do Balanço Patrimonial de $R \$$ $165.582,28$ a mais pelo método do valor justo decorrente da avaliação ao valor de mercado na data da elaboração do demonstrativo, atendendo aos critérios de avaliação e mensuração do CPC 29, contemplando o valor justo para evidenciar os ativos biológicos, composto por matrizes, novilhas e bezerras. Esta situação indica que a avaliação pelo valor justo dos ativos biológicos contribui com os gestores na identificação do real valor do patrimônio e melhor avaliação da performance da atividade.

Os resultados do presente estudo corroboram com os achados de Silva Filho, Martins e Machado (2013), em relação à geração de diferenças positivas significativas nos ativos biológicos. Além disso, a mensuração a valor justo tornou-se significativa, pois não considerou os custos na data em que efetivamente foram gerados, mas sim o valor atualizado e corrigido do mercado ativo, relacionado com o valor que compradores e vendedores estão dispostos a negociar.

\section{CONSIDERAÇÕES FINAIS}

Considerando as duas formas de mensuração dos elementos patrimoniais estudadas por meio da utilização do Balanço Patrimonial, da Demonstração do Resultado do Exercício e dos critérios estabelecidos e amparados pelo CPC 29 (2009), evidenciou-se as principais diferenças entre a avaliação pelo custo histórico e valor justo. Observou-se que o custo histórico é menos subjetivo e não depende de quem esteja avaliando os ativos, pois o valor contabilizado encontra-se em registros/documentos, a aplicabilidade do custo histórico não gera dificuldades de utilização, uma vez que permite ser apurado com base em movimentos financeiros reais. No entanto, a mensuração a valor justo requer conhecimento do mercado financeiro ou mercado ativo, a fim de avaliar corretamente os ativos biológicos pelo valor justo de cada bem, considerando suas características individuais.

No decorrer do estudo tais diferenças foram notáveis: (i) na conclusão da análise da situação financeira da propriedade verificou-se que o saldo do balanço patrimonial foi aproximadamente $14 \%$ superior, quando considerada a mensuração pelo valor justo em comparação com a mensuração pelo custo histórico. Essa diferença positiva provocada no saldo do Balanço Patrimonial representa um ganho econômico maior para a entidade, pois considera o preço de mercado ativo dos ativos biológicos (animais vivos), neste caso o valor justo foi superior ao custo.

Por considerar os atuais valores de mercado, a mensuração pelo valor justo permite ainda a fiel evidenciação da situação financeira e do patrimônio das entidades, o que não é possível por meio do custo histórico já que este não leva em conta a variação da moeda nos custos relativos às depreciações, amortizações e exaustões.

Recomenda-se que o valor justo deva ser utilizado sempre que possível (apuração da situação financeira mais próxima da realidade), a não ser quando não houver confiança nos valores avaliados e/ou estimados. Os proprietários rurais das entidades a serem mensuradas e avaliadas devem atentar ainda na escolha do profissional mensurador, o qual deve ser capacitado e conhecedor do mercado financeiro ou entendedor do processo. 


\section{REFERÊNCIAS}

BARROS, C. C.; DE SOUZA, F. J. V.; ARAÚJO, A. O., SILVA, J. D. G., SILVA, M. C.. O impacto do valor justo na mensuração dos ativos biológicos nas empresas listadas na BM\&F BOVESPA. Revista de Contabilidade do Mestrado em Ciências Contábeis da UERJ, v. 17, n. 3, p. 41-59, 2013.

COMITÊ DE PRONUNCIAMENTOS CONTÁBEIS. Interpretações e orientações técnicas contábeis, 1 ed. CFC, 2009.

CREPALDI, S. A.. Contabilidade rural: uma abordagem decisorial. 7. ed. São Paulo: Atlas, 2012.

ERNST \& YOUNG; FIPECAFI. Manual de normas internacionais de contabilidade: IFRS versus normas brasileiras. São Paulo: Atlas, 2010.

IUDÍCIBUS, Sérgio de. Teoria da contabilidade. 10. ed. São Paulo: Atlas, 2010.

KRUGER, S. D.; TRES, N.; OENNING, V.; ZANIN, A.; GUBIANI, C. A. Gestão das propriedades rurais do Oeste de Santa Catarina: as fragilidades da estrutura organizacional e a necessidade do uso de controles contábeis. Revista Catarinense da Ciência Contábil - CRCSC, v. 13, n. 40, p.09-19, 2014.

MALLMANN, M. S.; LAGO, I. C. Os agricultores e a "modernidade": uma análise da relação entre cultura e tecnologia no meio rural de CERRO LARGO/RS. Extensão Rural, Santa Maria, v. 19, n. 1, p. 12, 2012.

MARION, J. C.. Contabilidade rural: contabilidade agrícola, contabilidade da pecuária. 13. ed. São Paulo: Atlas, 2012.

MARTINS, V. G.. Mensuração de ativos financeiros a valor justo: análise da relevância da informação e da confiabilidade da mensuração na perspectiva do mercado brasileiro de capitais. In: Congresso USP: Controladoria e Contabilidade, 2013. XIII Congresso USP Controladoria e Contabilidade, São Paulo. Anais... São Paulo, 2013.

MEDEIROS, R. M. P. S. G.. NCRF 17 versus POC: Activos biológicos e produtos agrícolas no ponto de colheita. 2009. 80 f. Projeto (Mestrado em Contabilidade Avançada e Fiscalidade) - ISCTE Business School - Instituto Universitário de Lisboa, 2009.

OLIVEIRA, N. C.. Contabilidade do agronegócio: teoria e prática. 2. ed. Curitiba: Juruá, 2010.

PAULO, E.; CARVALHO, F. S.; SALES, I. C. H.; IKUNO, L. M.. Ativos biológicos: evidenciação das empresas participantes do lbovespa. In: CONGRESSO NACIONAL DE ADMINISTRAÇAO E CIÊNCIAS CONTÁBEIS, 2., 2011. Rio de Janeiro. Anais... Rio de Janeiro: Adcont, 2011.

RECH, I. J.; PEREIRA, I. V.; OLIVEIRA, J. R.. Impostos diferidos na atividade pecuária originados da avaliação dos ativos biológicos pelo valor justo: um estudo de 
seu reconhecimento e evidenciação nas maiores propriedades rurais do estado de Mato Grosso. Universo Contábil, Blumenau, v. 4, n. 2, p. 42-58, abr./jun. 2008.

SANTOS, G. J.; MARION, J. C.; SEGATTI, S. Administração de custos na agropecuária. 3. ed. São Paulo: Atlas, 2002.

SEGALA, C. Z. S.; SILVA, I. T.. Apuração dos custos na produção de leite em uma propriedade rural do município de Irani/SC. Custos e @gronegócioonline, v. 3, n. 1, Jan/Jun 2007.

SIMONETTI, D.; PERONDI, M. A.; KIYOTA, N.; VILLWOCK, A. P. S. Diversificação da renda e agregação de valor na agricultura familiar: lições a partir de uma comunidade rural. Extensão Rural, Santa Maria, v. 20, n. 2, p. 13, 2013.

SILVA FILHO, A. C. C.; MARTINS, V. G.; MACHADO, M. A. V. Adoção do valor justo para os ativos biológicos: análise de sua relevância em empresas brasileiras. Revista Universo Contábil, v. 9, n. 4, p. 110-127, 2013.

SILVA FILHO, A. C. C.; VERAS MACHADO, M. A.; REIS MACHADO, M. CONGRESSO USP DE CONTROLADORIA E CONTABILIDADE, 12; Custo histórico $x$ valor justo: qual informação é mais value relevant na mensuração dos ativos biológicos? 2012, São Paulo. Anais... São Paulo, 2012.

SILVA, R. A. G.. Administração Rural: teoria e prática. 2. ed. Curitiba: Juruá, 2009. 